\title{
Progesterone vaginal ring: Results of an acceptability study in
} Nigeria

Salisu Mohammed Ishaku

Population Council

Afolabi Kayode

Godwin Unumeri

Population Council

Ayodeji Oginni

Population Council

Adekunle Adeyemi

See next page for additional authors

Follow this and additional works at: https://knowledgecommons.popcouncil.org/departments_sbsr-rh

Part of the Demography, Population, and Ecology Commons, Family, Life Course, and Society Commons, International Public Health Commons, and the Women's Health Commons How does access to this work benefit you? Let us know!

\section{Recommended Citation}

Ishaku, Salisu Mohammed, Afolabi Kayode, Godwin Unumeri, Ayodeji Oginni, Adekunle Adeyemi, Deepa Rajamani, Heather Clark, Naomi Rijo, and Saumya RamaRao. 2015. "Progesterone vaginal ring: Results of an acceptability study in Nigeria." New York: Population Council. 


\section{Authors}

Salisu Mohammed Ishaku, Afolabi Kayode, Godwin Unumeri, Ayodeji Oginni, Adekunle Adeyemi, Deepa Rajamani, Heather Clark, Naomi Rijo, and Saumya RamaRao 


\section{PROGESTERONE VAGINAL RING:} RESULTS OF AN ACCEPTABILITY STUDY IN NIGERIA

Salisu Ishaku

Afolabi Kayode Godwin Unumeri Ayodeji Babatunde Oginni Adekunle Adeyemi Deepa Rajamani Heather Clark Naomi Rijo Saumya RamaRao 


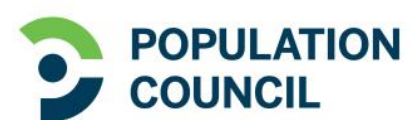 \\ Ideas. Evidence. Impact.}

The Population Council confronts critical health and development issues-from stopping the spread of HIV to improving reproductive health and ensuring that young people lead full and productive lives. Through biomedical, social science, and public health research in 50 countries, we work with our partners to deliver solutions that lead to more effective policies, programs, and technologies that improve lives around the world. Established in 1952 and headquartered in New York, the Council is a nongovernmental, nonprofit organization governed by an international board of trustees.

Population Council

House 4, No. 16b, POW Mafemi Crescent

Abuja, Nigeria

Tel: +234092914878

Fax: +234806 7787750

popcouncil.org

Suggested citation: Ishaku, Salisu, Afolabi Kayode, Godwin Unumeri, Ayodeji Babatunde Oginni, Adekunle Adeyemi, Deepa Rajamani, Heather Clark, Naomi Rijo, and Saumya RamaRao. 2015.

"Progesterone Vaginal Ring: Results of an Acceptability Study in Nigeria." Nigeria: Population Council.

(c) 2015 The Population Council, Inc. 


\section{Table of Contents}

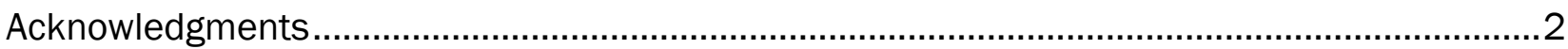

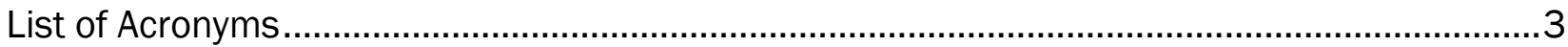

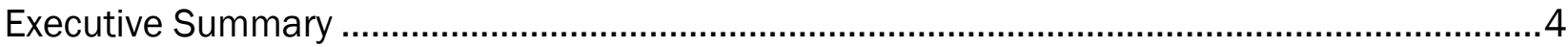

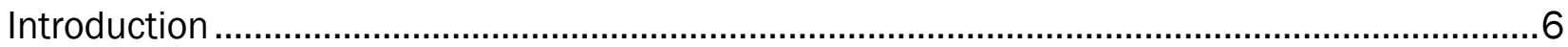

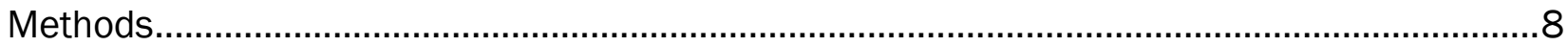

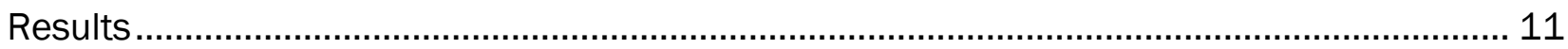

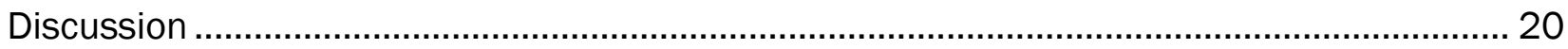

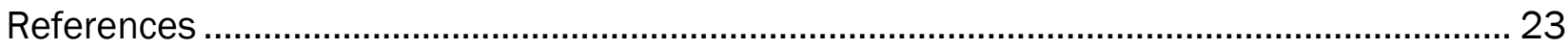

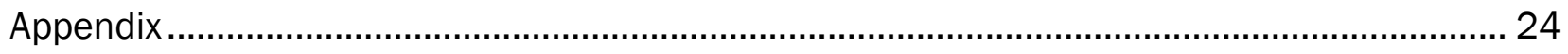




\section{Acknowledgments}

This report is based on a project that was funded by the Bill \& Melinda Gates Foundation that aimed to determine the acceptability of the Progesterone Vaginal Ring (PVR). The project was implemented by the Population Council in collaboration with the Ministry of Health in Nigeria. Ethics approvals were granted by the Institutional Review Board (IRB) of the Population Council, Federal Capital Health Research Ethics Committee (FCHREC) and the Institute for Advanced Medical Research and Training (IAMRAT), University of Ibadan, and research and import approval was granted by the National Agency for Food and Drug Administration and Control (NAFDAC).

We acknowledge all stakeholders (government, private, and nonprofit agencies) and individuals (Dr. David Chikamata, Dr. Juma Mwangi, and Dr. Kumudha Aruldas of the Population Council, Delhi) who provided valuable input in the design and/or implementation of the project. The successful completion of the study would not have been possible without the dedication of service providers in the participating health facilities (Wuse General Hospital, Abuja, and University College Hospital, Ibadan) and research assistants. We further acknowledge all the study participants who provided valuable information during the course of the study. 


\section{List of Acronyms}

\begin{tabular}{|c|c|}
\hline $\mathrm{AE}$ & Adverse Event \\
\hline CHEW & Community Health Extension Worker \\
\hline CPR & Contraceptive Prevalence Rate \\
\hline CRF & Case Report Form \\
\hline CSO & Civil Society Organization \\
\hline EML & Essential Medicines List \\
\hline FCHREC & Federal Capital Health Research Ethics Committee \\
\hline FGD & Focus Group Discussion \\
\hline $\mathrm{FMoH}$ & Federal Ministry of Health \\
\hline GCP & Good Clinical Practice \\
\hline GT & Galaxy Tablet \\
\hline HPV & Human Papillomavirus \\
\hline IAMRAT & Institute for Advanced Medical Research and Training \\
\hline IDI & In-depth Interview \\
\hline IRB & Institutional Review Board \\
\hline IUD & Intrauterine Contraceptive Device \\
\hline MEC & Medical Eligibility Criteria \\
\hline $\mathrm{MOH}$ & Ministry of Health \\
\hline NAFDAC & National Agency for Food and Drug Administration and Control \\
\hline NDHS & Nigeria Demographic and Health Survey \\
\hline NURHI & Nigerian Urban Reproductive Health Initiative \\
\hline $\mathrm{PI}$ & Principal Investigator \\
\hline PVR & Progesterone Vaginal Ring \\
\hline RHSC & Reproductive Health Supplies Coalition \\
\hline SAE & Serious Adverse Event \\
\hline SSA & Sub-Saharan Africa \\
\hline TFR & Total Fertility Rate \\
\hline WHO & World Health Organization \\
\hline
\end{tabular}




\section{Executive Summary}

\section{INTRODUCTION}

The progesterone vaginal ring (PVR) is a ring-shaped device used by women in the postpartum period to extend the contraceptive effectiveness of lactational amenorrhea. The ring is inserted in the vagina 6-9 weeks postpartum (for study purposes; 30-90 days in normal service delivery conditions) for continuous use for up to 3 months and replaced with a new ring if breastfeeding is continued and extended contraception is desired. The ring diffuses a continuous flow of low-dose progesterone through the vaginal walls, which enters the bloodstream and regulates the woman's fertility by suppressing ovulation. Previous studies showed that contraceptive vaginal rings are safe, effective, and well accepted in varied cultural settings. However, the extent to which the ring is acceptable in the sub-Saharan African context is unknown, especially since vaginal rings are a new technology and use of vaginal products such as tampons is limited in the region.

\section{STUDY OBJECTIVES}

This study examined the acceptability of the PVR in Nigeria as part of a larger project that was also conducted in Kenya and Senegal. The specific objectives of the study were to assess the factors influencing the acceptability of the method among clients, their partners, providers, community members, and those who were counseled but did not choose the method, to inform future introduction efforts.

\section{METHODS}

The study involved follow-up of participants who chose the ring, interviews with providers at baseline and endline, as well as cross-sectional interviews with women who were counseled on but did not choose the ring (PVR nonusers) and key stakeholders. A total of 58 women were enrolled for follow-up, another 5 were enrolled for in-depth interviews, and 58 PVR nonusers were interviewed upon exit. Women were enrolled for up to 6 months or 2 ring cycles. Data collection involved completion of case record forms (CRFs) by providers during enrollment; quantitative exit interviews with clients during enrollment, at 3 months and at 6 months following ring use or at discontinuation; quantitative exit interviews with PVR nonusers; in-depth interviews with a subset of PVR users at 1 month, 3 months, and 6 months following ring use; in-depth interviews with spouses of PVR users at endline; focus group discussions with community leaders at endline; and self-administered interviews with providers at baseline and endline. Analysis of the quantitative data entailed simple frequencies. Directed content analysis techniques were employed for analyzing the qualitative data.

\section{KEY FINDINGS}

- Acceptability of the ring: The majority of participants who completed the two ring cycles indicated that they would use the ring in the future (92\%), their partners or family members would support future use (95\%), they would recommend or had already recommended the ring to their friends or family members ( $100 \%$ and $86 \%$, respectively), and that they were willing to pay for the method (71\%).

- Reasons for choosing the ring: The most commonly cited reason among those who chose the PVR was that the method was provided free of charge (47\%). The second and third reasons were that the method was user-controlled (36\%) and perceived to have fewer side effects (35\%). Most participants also found the ring easy to insert, remove, and reinsert. 
- Client profile: Among the women who chose the PVR, 47\% were between the ages of 20 and 29, had at least secondary level education (45\%), and resided in urban or peri-urban areas (98\%). In addition, all the women who participated in the study were married (100\%) and 50\% wanted to space the next birth by at least two years.

- Prior use of family planning: The majority of the women were first-time contraceptive users (62\%). Among women who had previously used a method, the methods ever used were: pills (7\%), injectables (10\%), implants (9\%), emergency contraceptive pills (2\%), male condoms (7\%), and intrauterine contraceptive devices (IUDs) (3\%).

- Discontinuation of use: Participants who discontinued use of the ring did so for various reasons including experiencing side effects, personal discomfort, misconception about the method, and experiencing an adverse event.

\section{IMPLICATIONS}

- Findings from the study indicate that women and their partners, as well as family planning service providers, have positive attitudes toward the PVR, which is vital to its acceptance within the larger society.

- Findings from the study also suggest that the PVR could be a value-adding innovation for birth spacing in Nigeria. This is supported by the fact that the age distribution of participants and the proportion of first-time users of contraception among them coincided with the age groups and category of women where unmet need for family planning services is the highest.

- Eighty-one percent of participants chose to continue using the PVR for up to 6 months compared with the national average rate of contraceptive continuation in Nigeria of $50 \%$, suggesting high acceptance of the PVR that could contribute to an increased contraceptive prevalence rate (CPR) in the country. National government, donor agencies, and implementing partners should pay special attention to meeting the contraceptive needs of women during the postpartum period in their overall strategies of improving maternal and child health.

- Rights-based approaches might prove beneficial for the uptake of this new technology since findings from this study indicate that $30 \%$ of users chose the PVR solely because it is userinitiated and controlled, which could insinuate a high value on autonomy.

- Concerted efforts to educate the community and family planning providers across the country are essential prior to the registration and introduction of the PVR. To this end, the Population Council has commenced engagement with Civil Society Organizations (CSOs) across the country for the sole purpose of reaching various levels of government, community stakeholders, and women's groups to ensure that anticipated obstacles are managed in a timely manner. Continuous engagement must be emphasized in order to place the ring within a rights-based framework, dispel misconceptions, and address concerns of potential users and providers. 


\section{Introduction}

The progesterone vaginal ring (PVR) is used to extend the contraceptive effectiveness of lactational amenorrhea among breastfeeding women. The ring is inserted in the vagina 6-9 weeks postpartum (for study purposes; 30-90 days in normal service delivery conditions) for continuous use for up to 3 months and replaced with a new ring if breastfeeding is continued and extended contraception is desired. Women can use four rings successively for up to one year postpartum. The PVR functions by diffusing a continuous flow of progesterone through the vaginal walls-approximately $10 \mathrm{mg}$ per day-which then enters the bloodstream and regulates the woman's fertility by suppressing ovulation. Progesterone also thickens the cervical mucus, thereby inhibiting sperm penetration into the uterus. Clinical trials showed that PVR is an effective contraceptive method (Sivin et al. 1997; Massai et al. 1999). The method was first registered in Chile and Peru in 1998 for use by postpartum women but has since been expanded to other Latin American countries, including Bolivia, the Dominican Republic, Ecuador, and Guatemala (Reproductive Health Supplies Coalition [RHSC] 2011).

Previous studies conducted by the Population Council have demonstrated that vaginal rings are well accepted in settings as culturally diverse as Australia, Egypt, Latin America, Singapore, and the United States (RHSC 2011). However, the extent to which PVR is acceptable in the sub-Saharan African context is unknown, especially since vaginal rings are a new technology in this setting and use of vaginal products such as tampons is limited in the region. An understanding of the acceptability of the ring is important for informing the introduction of the method in the region. Sub-Saharan Africa in particular presents an opportunity for expanding the use of the method given relatively long breastfeeding durations; high unmet need for contraception, especially during the postpartum period; and the potential for multiple channels of introducing the method to potential users, including public and private clinics as well as private pharmacies and community distribution systems (Haggerty and Rutstein 1999; Bradley et al. 2012). Moreover, since the use of PVR is predicated upon women breastfeeding at least four times a day, it provides an opportunity to promote breastfeeding while ensuring contraceptive protection, thereby benefiting both mothers and their infants.

To understand the extent of acceptability of the method, the Population Council conducted acceptability studies in Kenya, Nigeria, and Senegal. This report presents findings from the study in Nigeria. The study was one component of a number of activities, including global and national consultations with key stakeholders, assessments and documentation of the regulatory and procurement frameworks, and market segmentation and demand analysis aimed at informing the introduction of the method in the country.

\section{STUDY OBJECTIVES}

This study examined the acceptability of PVR in Nigeria as part of a larger project that was also conducted in Kenya and Senegal. The specific objective of the study was to assess the factors influencing the acceptability of the method among clients, their partners, providers, community members, and women who were counseled on but did not choose the method. 


\section{STUDY CONTEXT}

Nigeria, the most populous country in Africa, has a population of more than 173 million with a rate of natural increase of 2.8\% (PRB 2012); however, the country lags behind in most health indices. Rates of maternal and child mortality, after showing a slight decline in the past years, are now rising, and currently stand at $576 / 100,000$ and $128 / 1,000$ respectively, and the total fertility rate (TFR) is 5.5 (NDHS 2013). Currently, the unmet need for contraception in the postpartum period is $65 \%$ as opposed to $16 \%$ for regular use (NDHS 2013). Furthermore, while the total need for modern contraception among postpartum women between 9 and 12 months is approximately $80 \%$, the actual met need is only $15 \%$, resulting in an unmet need of $65 \%$ (Borda et al. 2010). Although $67 \%$ of women of reproductive age would prefer to space their pregnancies by two or more years, up to $23 \%$ of births occur within 24 months (NDHS 2013). This indicates a strong need to increase the accessibility of contraceptive options that would serve the needs of women in the postpartum period.

According to the 2013 NDHS, breastfeeding in Nigeria is very prominent with $97 \%$ breastfeeding prevalence; however, only $13 \%$ of all infants were exclusively breastfed from birth up to the age of 6 months. The median duration for any breastfeeding was 18.3 months, while the median duration for exclusive breastfeeding was less than 1 month (NDHS 2013).

Despite sound policy and programmatic interventions to increase uptake of contraceptives in Nigeria over the last two decades, the contraceptive prevalence rate (CPR) for modern methods is currently $10 \%$, which has not improved significantly from 3.5\% in 1999 (NDHS 2013) and remains one of the lowest in sub-Saharan Africa (SSA). Following the renewed global commitments culminating in the 2012 London Summit on Family Planning-which promised to reach an additional 120 million new users of quality modern contraceptives-the Federal Ministry of Health $(\mathrm{FMoH})$ in collaboration with reproductive health stakeholders in Nigeria has set an ambitious new target of raising the CPR from $10 \%$ to $36 \%$ by 2018 . As part of the effort to achieve this objective, meeting the contraceptive need of women in the immediate postpartum period and beyond is an integral component of the renewed commitment. Consequently, greater emphasis must be placed on making contraceptives that are proven effective for postpartum use, such as the PVR, and are easily accessible and available.

Based on recent trends in current use of family planning methods, the PVR has the potential to be an effective family planning method for women in the postpartum period. Understanding the extent of acceptability of the PVR will be crucial in determining how best this contraceptive technology would be placed within the existing health systems framework in sub-Saharan Africa. 


\section{Methods}

During this study, both quantitative and qualitative data were collected from the women who participated (users) and their partners, healthcare providers who enrolled and monitored the users, women who opted not to use the ring (nonusers), and key community stakeholders.

\section{STUDY DESIGN}

A total of 97 women were screened across the two sites; of those, 58 were eligible and recruited to participate in the study. Potential study participants were counseled on all contraceptive options appropriate for use during the postpartum period when referred for family planning services. Women who chose the PVR were instructed that the use of the ring entailed enrollment in a study and were given detailed information about the ring so that their consent to participate in the study was well informed.

Women were eligible to participate in the study if they could provide informed consent, met all the inclusion criteria, and did not meet any of the exclusion criteria. Inclusion and exclusion criteria can be found in Appendix A.

Study participants were followed prospectively to measure the ring's acceptance (continuation rate and satisfaction) for up to 6 months (2 ring cycles) or discontinuation. Data were collected from users by means of a quantitative survey questionnaire. To complement the quantitative data, qualitative data were collected from 5 additional women to better understand the intricacies of everyday use, through an in-depth interview questionnaire. Providers were also interviewed pre- and post-training and at study end using a questionnaire guide. Focus group discussions (FGDs) were held with other stakeholders who may have some influence on users' behaviors.

Once the enrollment target of 58 women was achieved, an additional 5 women were screened and recruited to participate in an in-depth interview (IDI). They completed a separate informed consent form and were also interviewed at months 1,3 , and 6 .

\section{STUDY SETTING}

The study was conducted at Wuse General Hospital in Abuja and University Hospital in Ibadan. Study sites were selected in conjunction with the Ministries of Health ( $\mathrm{MOH}$ ) based on onsite availability of postpartum family planning services, affiliation with the Nigerian Urban Reproductive Health Initiative (NURHI), and ability to meet research standards and global Good Clinical Practice (GCP) guidelines.

\section{STUDY PROCEDURES}

The study was preceded by a mapping exercise that involved consultative meetings with key government, regulatory, and development agencies; social marketing organizations; research institutions; manufacturers/distributors of health commodities; community/advocacy groups; institutions involving public/private partnerships; and other organizations providing family planning services in the country. The purpose of the exercise was to determine the perspectives of the stakeholders regarding the method and the acceptability study. The next step involved obtaining the ethical, research, and regulatory approvals necessary for importation of rings into the country and for conducting the study. 


\section{Ethics Clearances}

As this study was part of a larger multicountry acceptability study, the joint study protocol was first reviewed and approved by the Population Council's Institutional Review Board (IRB) in New York. Subsequently, the protocol was revised for further review by ethics committees in the Federal Capital Territory (FCT), Abuja, and University of Ibadan where the study was carried out. The local committees, FCT Health Research Ethics Committee and the Institute for Advanced Medical Research and Training (IAMRAT), reviewed and approved the protocol on December 12, 2012, and November 15, 2012, respectively. In each case, the approval was renewed for one additional year due to a delay in commencing the study. As a final step, the study protocol was reviewed, approved, and registered by the National Agency for Food and Drug Administration and Control (NAFDAC).

\section{Ring Importation}

An importation permit was granted by NAFDAC (NAFDAC/DER/CT/PVR/VOL.1) on August 14, 2013. The rings were imported directly from the manufacturer Grunenthal, with headquarters in Chile, to the Population Council office in Nigeria, which subsequently distributed the rings to the study facilities in Wuse General Hospital in Abuja and the University College Hospital in Ibadan. The rings were shipped in two batches. The first batch of 190 rings was imported and received on October 2, 2013, and the second batch of 125 rings was received on January 29, 2014.

\section{Training of Providers and Data Collectors}

Trainings sessions were coordinated and conducted with obstetricians and gynecologists, service providers, and nurses prior to study initiation. Four providers and 5 data collectors who were directly involved in the study were trained. In addition, 28 obstetricians and gynecologists selected from tertiary hospitals across the country were trained to serve as a pool of local trainers in the country.

\section{Sites Initiation and Monitoring}

Monitoring visits to each site to ascertain capacity and readiness to accommodate the study also occurred prior to study initiation. The sites were assessed in terms of their capacity to provide 24-hour service, a private space for provider/client interaction (including counseling), availability of pregnancy and HIV screening kits, availability of cabinets where data and research commodities could be locked, and sufficient client load. Subsequently, providers and monitors maintained a facility binder designed to keep track of all activities that occurred at the project sites. In addition, the study monitor conducted regular site visits to ensure compliance with study procedures, good clinical practice, ethical conduct of the study, and recordings of adverse and serious adverse events, if any. Participants were also instructed to report all side effects, including adverse or serious adverse events (AEs or SAEs), while providers were trained to ask about and record all side effects that women reported.

\section{Recruitment and Enrollment of Study Participants}

The recruitment process entailed providers counseling postpartum clients seeking family planning services on all available methods including PVR, so that all clients had a choice of methods. Clients who were identified from other units, such as immunization and growth monitoring, were encouraged to visit the family planning unit if they needed contraceptive services. Clients who chose the ring during counseling were directed to the research assistant who completed the written informed consent process before providers could dispense the method. Clients were informed about study procedures, including the requirement to undergo pregnancy and HIV tests as part of inclusion and exclusion criteria, as well as the need for follow-up. Those clients who granted written informed consent were directed back to the provider for medical examination. Clients who qualified for the ring after satisfying the inclusion and exclusion criteria were then specifically counseled on the method and shown how to use it. Enrollment began at both sites in January 2014 and was completed in July 2014. The last woman exited the study at both locations in January 2015.

Providers were instructed to show enrolled participants how to insert and remove the ring, and to ensure that they left the facility with the ring properly inserted. In particular, providers were trained to insert the ring, 
ask participants to remove it and reinsert themselves, and to confirm that they were not feeling it after reinsertion before leaving the facility. Clients who did not grant written informed consent and those who did not satisfy the inclusion and exclusion criteria after screening were offered other methods, even if they had initially chosen the ring. Clients who were given the ring were then interviewed by the research assistants upon exit. They were advised to return to the facility after three months (with the used ring) to obtain another one, or at any time in case of concerns regarding the use of the ring. During exit interviews, the research assistants obtained contact information to follow up with the clients in the event that they did not return to the study site. Given that the ring was being introduced in the context of a study, there were elaborate inclusion and exclusion criteria as outlined in the Appendix.

\section{DATA COLLECTION, MANAGEMENT, AND ANALYSIS}

The data collection process was guided by Case Report Forms (CRFs) that were designed to capture information on specific aspects of the research project. Each study participant completed an initial CRF to screen for eligibility to participate and to record information on medical history at baseline. Completion of additional CRFs was requested at various times; the forms recorded information on: 1) adverse events; 2) follow-up visits at months 1,3 and 6; 3) missed visits; 4) pregnancy notification, pregnancy outcome, serious adverse events, early termination, and unscheduled visits. The additional CRFs were completed by the providers at the facilities as needed.

Two data collectors per clinical site were provided with Galaxy Tablets (GTs)-personal digital assistants fitted with two ODK-based questionnaires (Baseline Social and Follow-Up). An on-site obstetrician/gynecologist, also referred to as the Principal Investigator (PI), supervised the activities of the providers and data collectors on a daily basis.

The Principal Investigators provided continued mentorship on the principle of Good Clinical Practice (GCP) twice per month at each site to ensure that the study was progressing as designed and site researchers were following GCP guidelines. During any particular visit, study coordinators retrieved all recorded information from the software and immediately transferred the information electronically to the Population Council's central data management unit in Nairobi, Kenya, at which time the data were converted into a more accessible software (such as Stata and Excel) and sent back to the Nigeria country office for local analysis. The processed data were also shared with the Population Council's New York office and stored as backup and for use in the multicountry pooled analysis. 


\section{Results}

\section{OVERALL STUDY METRICS}

A total of 97 women were screened for eligibility to participate. Of these 97 , a total of 58 women were enrolled (Table 1). For every enrolled participant, a nonuser (a woman who did not choose to use the vaginal ring) was administered a short questionnaire on her method choice (after providing informed consent).

Out of the 58 women who enrolled in the study, 47 (81\%) completed the study, meaning they completed the two-ring cycle (or 6 months). Only 5 women (8.6\%) reported adverse events associated with the use of the PVR. There was no case of a serious adverse event (SAE) defined as the development of any lifethreatening medical condition or any condition that leads to a woman being admitted in a hospital while on the PVR, irrespective of the cause of the morbidity.

\section{DEMOGRAPHIC CHARACTERISTICS OF STUDY PARTICIPANTS}

Nearly all women in this study (58) were above the age of 20 years, with only 1 participant under 20 years of age (Table 2). Women between the ages of 20-29 and 30-39 were fairly equally represented, $46.6 \%$ and $51.7 \%$, respectively (Table 2). In Nigeria, while the average unmet need for spacing is $12 \%$, unmet need for women between the ages of 20-29 and 30-39 is $31.8 \%$ and $22.6 \%$, respectively (NDHS 2013). This observation indicates the potential of the PVR to address the disproportionately high unmet need in these age groups.

Most of the participants were from urban $(60.3 \%)$ and peri-urban (37.9\%) areas, which conformed to the fact that both Wuse General Hospital in Abuja and $\mathrm{UCH}$ Ibadan are urban facilities. However, one participant from a rural area also chose to use the ring. Almost all the participants or users of the PVR completed secondary education or above (98.3\%). About $80 \%$ of the participating women were gainfully employed, with up to $40 \%$ reporting employment in a professional occupation. In addition, all the women that participated in this study were married.
TABLE 1 Rate of enrollment and participation in study

\begin{tabular}{lc}
\hline Variable & (n) \\
\hline Number of women screened & 97 \\
Number of women enrolled & 58 \\
Number of women who completed the study & 47 \\
(used two rings) & 58 \\
Number of PVR nonusers & 5 \\
Number of Adverse Events & 0 \\
\hline
\end{tabular}

Data source: CRFs and Baseline survey.

TABLE 2 Demographic characteristics of study participants

\begin{tabular}{|c|c|c|}
\hline Variable & $(n)$ & Percent \\
\hline \multicolumn{3}{|l|}{ Age } \\
\hline$<20$ & 1 & 1.7 \\
\hline $20-29$ & 27 & 46.6 \\
\hline $30-39$ & 30 & 51.7 \\
\hline \multicolumn{3}{|l|}{ Place of residence } \\
\hline Urban & 35 & 60.3 \\
\hline Peri-Urban & 22 & 37.9 \\
\hline Rural & 1 & 1.7 \\
\hline \multicolumn{3}{|l|}{ Education } \\
\hline Primary & 1 & 1.7 \\
\hline Secondary & 26 & 44.8 \\
\hline College & 14 & 24.1 \\
\hline University & 17 & 29.3 \\
\hline \multicolumn{3}{|l|}{ Occupation } \\
\hline Not Working & 12 & 20.7 \\
\hline Nonprofessional & 23 & 39.7 \\
\hline Professional & 23 & 39.7 \\
\hline \multicolumn{3}{|l|}{ Marital Status } \\
\hline Married & 58 & 100.0 \\
\hline \multicolumn{3}{|l|}{ Partner's Occupation } \\
\hline Not Working & 33 & 39.7 \\
\hline Nonprofessional & 0 & 0 \\
\hline Professional & 34 & 58.6 \\
\hline
\end{tabular}

Data source: Baseline survey. 


\section{REPRODUCTIVE AND FAMILY PLANNING HISTORY}

In this study, the majority of the participating women (64\%) had less than 3 children at the time of enrollment, while $29 \%$ had between 3 and 5 children. (Table 3.) About $30 \%$ of pregnancies following the index birth in this study were unintended. The majority of the women in this study (72\%) expressed that they would like to space their next pregnancy by at least 2 years. Wider availability of the PVR could provide an opportunity to mitigate the substantial unmet need for these women.

TABLE 3 Reproductive history and family planning use

\begin{tabular}{|c|c|c|}
\hline Variable & (n) & Percent \\
\hline \multicolumn{3}{|c|}{ Children ever born } \\
\hline$<3$ & 37 & 63.8 \\
\hline $3-5$ & 17 & 29.3 \\
\hline$>5$ & 4 & 6.9 \\
\hline \multicolumn{3}{|c|}{ Number of living children } \\
\hline$<3$ & 38 & 65.5 \\
\hline $3-5$ & 16 & 27.6 \\
\hline$>5$ & 4 & 6.9 \\
\hline \multicolumn{3}{|c|}{ Pregnancy was intended } \\
\hline Yes & 41 & 70.7 \\
\hline No & 17 & 29.3 \\
\hline \multicolumn{3}{|c|}{ Preferred spacing of next birth } \\
\hline $1-2$ years & 17 & 29.3 \\
\hline $3-5$ years & 25 & 43.1 \\
\hline $6-8$ years & 2 & 3.4 \\
\hline$>8$ years & 2 & 3.4 \\
\hline No response & 12 & 20.7 \\
\hline \multicolumn{3}{|c|}{ Discussed pregnancy spacing with partner } \\
\hline Yes & 56 & 96.6 \\
\hline No & 2 & 3.4 \\
\hline \multicolumn{3}{|c|}{ Prior use of a method } \\
\hline Ever used & 22 & 37.9 \\
\hline Never used & 36 & 62.1 \\
\hline
\end{tabular}

An important observation that is particularly relevant for the ring is what appeared to be a high culture of spousal communication for family planning among study participants. About $97 \%$ of the users have discussed spacing their pregnancies with their spouses. Also, up to $62 \%$ of participating women are first-time users of family planning in general. In a society where decisions to use a method are predominantly informed by recommendations of friends and family members, to observe that more than half of the women are first-time users of family planning is very encouraging and bodes well for acceptability of the PVR in the general population.

Out of $38 \%$ of users who have ever used a method, the most common method used was injectable contraceptives (10\%). (Figure 1.) This is in line with the existing knowledge that injectables are the most used methods in Nigeria (NDHS 2003 and 2008). Closely following injectables are implants (9\%), contraceptive pills and male condoms (both 7\%), IUDs (3\%), and emergency contraceptive pills (2\%).

\section{FIGURE 1 PREVIOUS METHOD USE AMONG USERS}

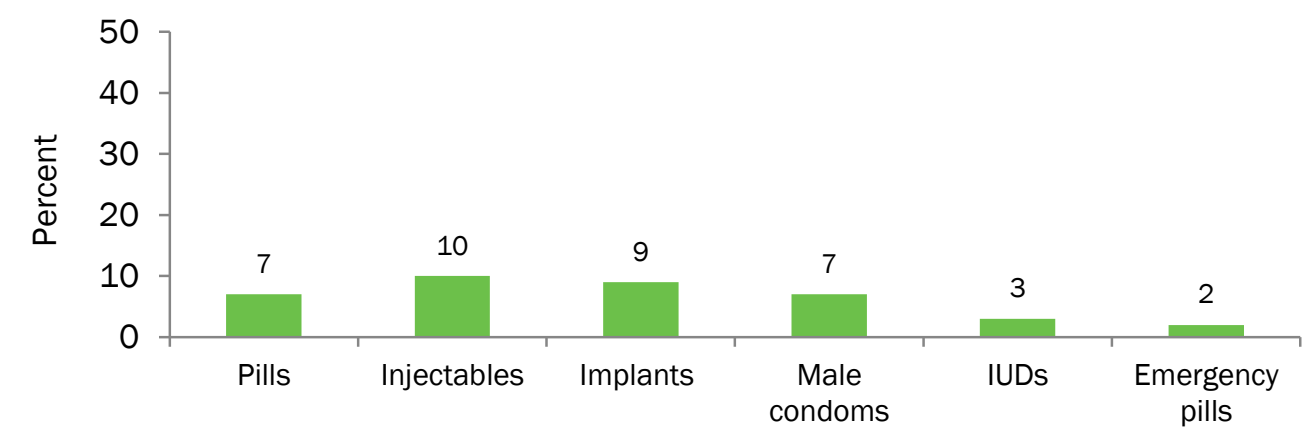

Data source: Baseline survey. 


\section{INITIAL IMPRESSIONS}

At the time of enrollment, prospective study participants were asked to provide their impressions of the PVR in respect to color, size, and texture. (Figures 2, 3, 4.) Most of the study population (91\%) felt that the color was just fine. Only $7 \%$ felt that the ring was too bright. In respect to the ring's size, up to $43 \%$ of participants at enrollment expressed that the ring was larger than ideal, although $55 \%$ felt that the ring's size was just fine. The same also goes with impressions of the ring's texture, as 52\% felt that the texture was just fine while $35 \%$ thought it was too soft. However, these initial impressions appear to have changed during the duration of the study, particularly when participants were reinterviewed at follow-up visits.
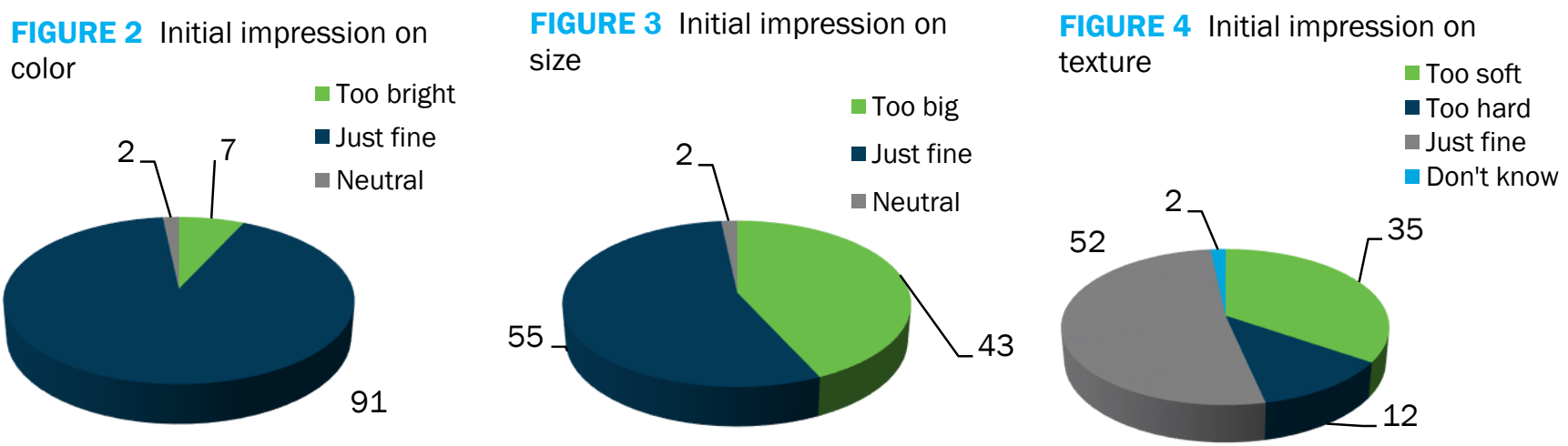

\section{METHOD CHOICE (PVR USERS VS NONUSERS)}

Participating women expressed a wide range of opinions as to why they chose the vaginal ring over other available methods presented to them. Although no opinion was mutually exclusive, at least $35 \%$ of women indicated fewer side effects and $36 \%$ indicated the fact that the PVR is user-controlled as reasons why they chose the ring. (Figure 5.) The fact that the ring was given free of charge contributed to some of the reasons why $47 \%$ of the women opted for the ring, while another $16 \%$ were attracted by the fact that it's short-acting.

The majority of women in this study who did choose another method $(47 \%)$ did so because they knew someone who had used their method of choice in the past. (Figure 6.) This is in conformity with our knowledge that women decide on family planning methods based on referrals from their significant others. Similarly, $17 \%$ of nonusers of the PVR continued using the methods they were familiar with, while $22 \%$ made their choice based on the perception that the method is easy to use. Lastly, about $10 \%$ of nonusers made their choice based on other nonspecific reasons. An important observation here is that while the majority of family planning users are using methods that were previously known to them or those that were recommended by friends and family members, it was possible to identify 97 women from the two facilities who expressed interest in using the vaginal ring despite seeing and learning about it for the first time. Methods chosen by nonusers included IUDs, implants, injectable contraceptives, and contraceptive pills.

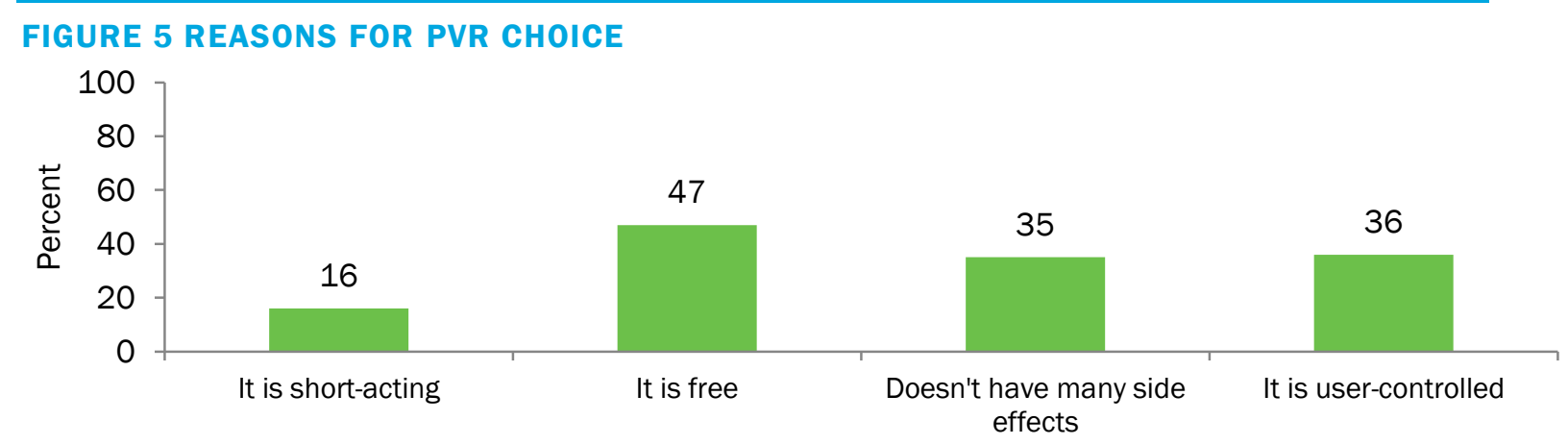

Data source: Baseline survey. 


\section{FIGURE 6 REASONS FOR OTHER METHOD CHOICE}

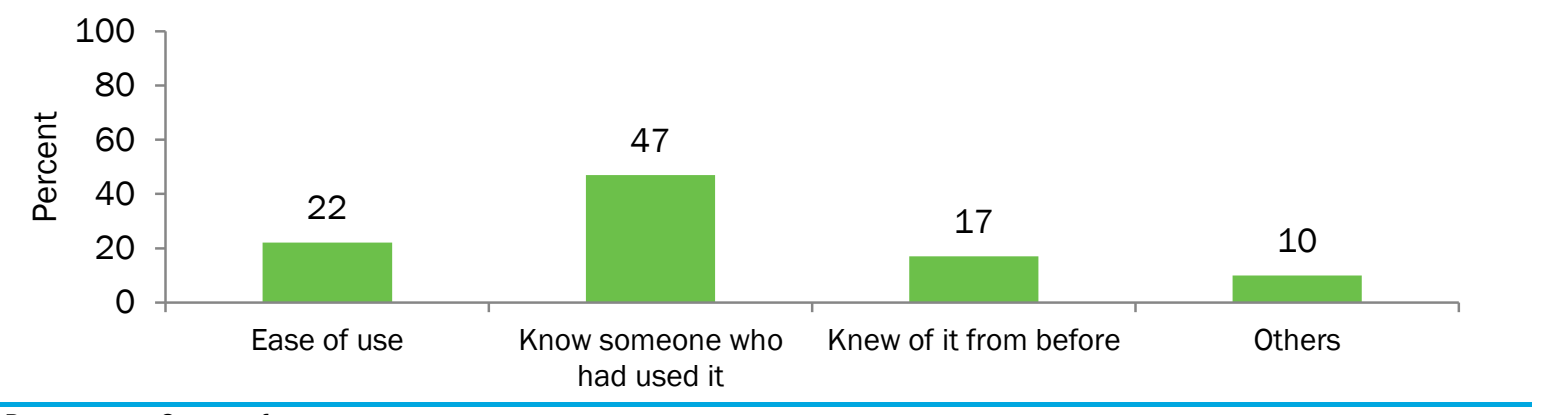

Data source: Survey of nonusers.

\section{PERCEIVED QUALITY OF CARE}

Proper counseling and provision of balanced information are integral to the success of effective family planning services, thus the recruiters were trained to provide correct and adequate information to ensure that the choice of the PVR, or other method, was well-informed. This was considered a measure of the quality of care the women received at enrollment. Results showed that women have received adequate and balanced information and the quality of care they received was judged to be standard as far as PVR use is concerned. For example, all 58 women confirmed that providers conveyed to them information on the minimum breastfeeding episodes per day required for the PVR to be effective as well as when to remove the ring, and have been encouraged to insert the rings by themselves before leaving the health facilities. (Table 4.) Nearly all the women (98\%) were given the opportunity to ask questions and seek clarification, and were taught how to remove the rings. This provides insight into how family planning service providers may interact with prospective ring users when the method is eventually registered and introduced in Nigeria.

TABLE 4 Perceived quality of care

\begin{tabular}{llcrr}
\hline Domain & Item & Response & (n) & Percent \\
\hline Counseling on & Provider conveyed minimum breastfeeding & Yes & 58 & 100 \\
the PVR method & requirement & Yes & 58 & 100 \\
& Provider conveyed when to remove PVR & Yes & 57 & 98 \\
& Provider allowed respondent to ask questions & Yes & 58 & 100 \\
& Provider encouraged respondent to insert PVR & & 58 & 100 \\
Counseling on & Provider showed how to insert PVR & Yes & 57 & 98 \\
PVR use & Provider showed how to remove PVR & Yes & 57
\end{tabular}

Data source: Baseline survey.

\section{ACCEPTABILITY}

As stated previously, acceptability in this study is measured by the continuation rate, user-related experiences and those of spouses, and opinions shared by providers and community stakeholders. The continuation rate at 6 months was $81 \%$. Other proxies of ring acceptability have been summarized in Table 5 . In this analysis, the study compared the responses of participants who reported satisfaction using the ring with responses of participants who reported dissatisfaction in relation to some variables of interest. For example, all those who reported satisfaction and dissatisfaction found it very easy to insert the rings, with ease of removing and reinserting insignificantly diminishing among the dissatisfied compared with the satisfied (86\%, 86\%, and 93\%, 100\%, respectively). 
TABLE 5 Responses by satisfaction related to PVR use

\begin{tabular}{|c|c|c|c|c|c|}
\hline Domain & Item & Response & Satisfied & $\begin{array}{c}\text { Not } \\
\text { satisfied }\end{array}$ & $\begin{array}{l}\text { p-value Fisher's } \\
\text { Exact Test }\end{array}$ \\
\hline \multirow[t]{3}{*}{ Ease of use } & Ease of inserting PVR & Easy/Very easy & 100 & 100 & 1.00 \\
\hline & Ease of removing PVR & Easy/Very easy & 93 & 86 & 0.59 \\
\hline & Ease of reinserting PVR & Easy/Very easy & 100 & 86 & 0.06 \\
\hline Side effects & Reported & No & 86 & 60 & 0.07 \\
\hline Expulsion & PVR fell out on its own & No & 97 & 100 & 1.00 \\
\hline \multirow[t]{4}{*}{ Sexual intercourse } & Felt PVR during sex & No & 79 & 60 & 0.23 \\
\hline & Partner felt PVR during sex & No & 71 & 60 & 0.48 \\
\hline & Change in frequency of sex & No & 84 & 79 & 0.37 \\
\hline & Change in sexual pleasure & Increase & 79 & 80 & 1.00 \\
\hline Will use in future & Interested & Yes & 92 & 40 & 0.00 \\
\hline $\begin{array}{l}\text { Partner/family would } \\
\text { support use }\end{array}$ & Reported & Yes & 95 & 20 & 0.00 \\
\hline Will recommend & Reported & Yes & 100 & 60 & 0.00 \\
\hline Already recommended & Reported & Yes & 86 & 50 & 0.02 \\
\hline Willingness to pay & Interested & Yes & 71 & 0 & 0.00 \\
\hline
\end{tabular}

Data source: Follow-up surveys.

Furthermore, the proportions of satisfied women who responded "yes" to whether they felt the rings during sex, whether their partners felt the ring, or whether the ring affected the frequency of intercourse were slightly higher than those of their counterparts. However, there is a significant difference with regard to desired future use of the ring among the dissatisfied than the satisfied. While $92 \%$ of the satisfied would be interested in using the ring in the future, only $40 \%$ of the dissatisfied showed similar interest. Similarly, while $95 \%$ of the satisfied users' partners/family would support the use of the ring and $100 \%$ of the satisfied users would recommend the ring, only $20 \%$ and $60 \%$ of the dissatisfied, respectively, would do the same. In the same vein, $71 \%$ of satisfied users would be willing to pay for the ring if it were available in the market while none of the dissatisfied users were willing to do so. In summary, while there is no significant difference in terms of ease of use of the ring between the satisfied participants and the dissatisfied, negative attitudes toward the ring seem to be mainly expressed among the dissatisfied. 


\section{WOMEN PARTICIPANTS}

TABLE 6 Responses by satisfaction related to PVR use

\begin{tabular}{ll}
\hline Domain & Comments \\
\hline $\begin{array}{l}\text { Effect on breast milk } \\
\text { Perceived side effects }\end{array}$ & $\begin{array}{l}\text { "Honestly, my breasts have never dry ... my breast is floating (meaning flowing)." } \\
\text { "It is just making me happy. It is just making me enjoy my marriage." }\end{array}$ \\
Effects on sex life & $\begin{array}{l}\text { "Yes, I am thinking ... although we were informed by the providers that the ring is safe. But I am still } \\
\text { afraid of it (the ring being expelled). But even after we have intercourse, the ring is still in place." }\end{array}$ \\
Self-insertion & $\begin{array}{l}\text { "I feel somehow because I have not done something like that before ... asked if whether I can put it } \\
\text { "I myself and I said no." } \\
\text { perfectly like say I be expert! Since I put it that day, the thing has not come out." }\end{array}$ \\
\hline
\end{tabular}

Note: Acceptability = continued $(2$ cycles), recommended, adhered, and will use in the future.

\section{MALE PARTNERS}

TABLE 7 Responses by satisfaction related to PVR use

\begin{tabular}{ll}
\hline Domain & $\begin{array}{l}\text { "Sometimes I ask her, this thing is not disturbing you? She say no, she is not feeling } \\
\text { anything. So I say okay." }\end{array}$ \\
"Texual intercourse & two first time when you enter, you will know there is something there. When we take \\
Continuation/discontinuation & "No! Even before she delivered this baby I told her after this baby it is family planning. \\
& So even two years to come now, we are not thinking about having any other baby."
\end{tabular}

Data source: In-depth interviews with husbands.

\section{PROVIDERS}

TABLE 8 Responses by satisfaction related to PVR use

\begin{tabular}{lll}
\hline Domain & Before study & After study \\
\hline Size of the ring & $\begin{array}{l}\text { Doubted if one size can fit all } \\
\text { and used the ring }\end{array}$ \\
Ring to stay permanently & $\begin{array}{l}\text { Thought it would interfere with sex } \\
\text { Women's comfort }\end{array}$ & $\begin{array}{l}\text { Perception changed with women who used it continuously } \\
\text { for } 6 \text { months }\end{array}$ \\
\hline & $\begin{array}{l}\text { Anxiety over discomfort if the ring is } \\
\text { inserted }\end{array}$ & This fear faded when women did not report any discomfort \\
\hline
\end{tabular}

Data source: Provider questionnaire (before and after). 


\section{COMMUNITY STAKEHOLDERS}

TABLE 9 Responses by satisfaction related to PVR use

\begin{tabular}{ll}
\hline Domain & \multicolumn{1}{l}{ Comments } \\
\hline Questions and concerns & $\begin{array}{l}\text { "What position is it going to take if it enters your vagina? And can it really prevent the } \\
\text { sperm from entering? The chemical ... is it dissolving the sperm when it is releasing or } \\
\text { what?" }\end{array}$ \\
Fear of effect on babies & "I think the chemical ... will have effect on their baby." \\
Perception of women using the ring "Most women will like to buy it secretly; they can easily do it, without letting their \\
\end{tabular}

Data source: Focus group discussion.

\section{PARTNERS' SUPPORT AND EXPERIENCE}

In general, the experiences of male partners were positive. Prior to the start of the study, stakeholders expressed concerns that women's partners might dislike the ring since it is inserted vaginally, because it might interfere with sex. In this study, only $15 \%$ of partners reported changes in their sexual pleasure when their female partners were using the ring and a further $8 \%$ felt that the perceived changes in sexual pleasure were due to the ring's presence in the vagina. (Figure 7.) Also, 23\% reported feeling the ring during intercourse. However, psychological components to these perceptions must be ruled out.
FIGURE 7 PARTNERS' REACTIONS ON PVR USE

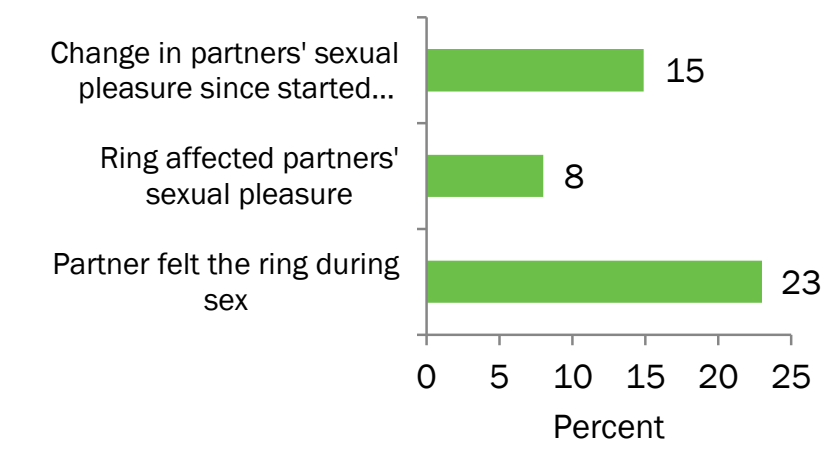

Data source: Follow-up surveys.

\section{CONTINUATION}

One measure of acceptability is the extent to which women continue to use the product. Table 10, below, presents the results of an analysis that explored the relationship, if any, between key aspects of the use experience and continued use through two ring cycles. The hypothesis being tested is that a positive use experience will have a positive effect on continuation.

In regards to the ease of use of the PVR, there was no difference among those who continued and those who terminated. Those who completed the study compared to those who terminated reported that it was easy and/or very easy to insert the ring. As a matter of fact, perception about the ease of removing the ring was better among terminators (100\%) than among completers (89\%). The general inference that can be made is that nearly all participating women believe that the ring is easy to insert and remove. 
TABLE 10 Responses by continuation related to PVR use

\begin{tabular}{|c|c|c|c|c|c|}
\hline Domain & Item & Response & $\begin{array}{c}\text { Completed } \\
(\%)\end{array}$ & $\begin{array}{l}\text { Terminated } \\
(\%)\end{array}$ & $\begin{array}{l}\text { p-value Fisher's } \\
\text { Exact Test }\end{array}$ \\
\hline \multirow[t]{3}{*}{ Ease of use } & Ease of inserting PVR & Easy/Very easy & 100 & 100 & 1.00 \\
\hline & Ease of removing PVR & Easy/Very easy & 89 & 100 & 0.57 \\
\hline & Ease of reinserting PVR & Easy/Very easy & 96 & 100 & 1.00 \\
\hline \multirow[t]{2}{*}{ Expulsion } & PVR fell out on its own & No & 91 & 50 & 1.00 \\
\hline & Frequency of feeling the PVR & $<1 /$ week or never & 79 & 100 & 1.00 \\
\hline \multirow{5}{*}{$\begin{array}{l}\text { Sexual } \\
\text { intercourse }\end{array}$} & Felt PVR during sex & No & 79 & 0 & 0.05 \\
\hline & Partner felt PVR during sex & No & 72 & 0 & 0.09 \\
\hline & Removal during sex & No & 95 & 50 & 0.11 \\
\hline & Change in frequency of sex & No change or increase & 85 & 0 & 0.03 \\
\hline & Change in sexual pleasure & No change or increase & 81 & 0 & 0.04 \\
\hline
\end{tabular}

Data source: Baseline and follow-up surveys.

One recurring concern among providers and clients alike was the possibility of the ring slipping out of the vagina and/or of partners feeling the ring during sexual intercourse; both of these concerns could affect adherence. Therefore, this study measured these experiences among those who completed the study compared with those who terminated. There was little difference among the terminators and completers in relation to whether the ring spontaneously fell out of place. For example, those who terminated never reported feeling the ring fall out of the vagina, and about $2 \%$ of those who completed the study reported this experience.

However, the completers reported more favorable experience than the terminators regarding the experience of their spouses feeling the vaginal ring during sexual intercourse. Virtually all terminators reported that both they and their spouses felt the ring, while only $21 \%$ and $28 \%$ of the women and their spouses, respectively, who completed reported the same. The reported experiences were similar for whether the use of the ring affected the frequency of intercourse or sexual pleasure. Significant differences were noted in the domain of the PVR falling out on its own and during sexual intercourse. Only $9 \%$ of continuers felt the PVR fall out, whereas $50 \%$ of terminators felt the same. While $79 \%$ of continuers reported not feeling the PVR during sex, $85 \%$ reported no change or an increase in frequency of sex. Eighty-one percent of continuers reported no change or an increase in sexual pleasure, while $0 \%$ of terminators reported the same.

As reported earlier, 11 out of the 58 enrolled women dropped out of the study without completing the two ring cycles. Not all women who discontinued the study returned to the facilities, and only three of the women who discontinued provided reasons for their actions. Of the three women who provided reasons, two expressed feeling uncomfortable with the ring and one stopped using the ring because she experienced symptoms of headache, dizziness, and fever and thus associated these symptoms with the use of the ring. (Figure 8.) In general, reasons provided for discontinuing the ring are nonspecific in nature and may not be connected to the use of the ring. 


\section{ADVERSE AND SERIOUS ADVERSE EVENTS}

There were only five cases of adverse events (AEs) recorded during the study. As mentioned earlier, an AE is said to occur when a woman who is using the ring reports any sign or symptom irrespective of the actual cause of the complaint. In this study, three women reported transient irregular vaginal bleeding, a common side effect associated with all progesterone-based family planning methods such as the PVR. In all cases, the women were counseled and each continued with the ring to the end of the study. Another participant provided a nonspecific complaint for which she received counseling and completed the study without further complaint. One woman complained of fever and headache, which was treated with analgesics. This participant subsequently dropped out of the study despite reassurance from the providers that the side effect was not serious. In general, this study did not record any $A E$ that can be said to be atypical of what is known of a progesterone-based contraceptive product. No serious adverse events were reported in this study. (Tables 11, 12.)

TABLE 11 Adverse events

\begin{tabular}{lll}
\hline Number & Description & Treatment \\
\hline $\mathbf{3}$ & Brief episode of bleeding & Reassurance by provider \\
$\mathbf{1}$ & Fever/headache & Provision of analgesics \\
$\mathbf{1}$ & $\begin{array}{l}\text { Nonspecific } \\
\text { complaint }\end{array}$ & Reassurance by provider \\
& Data source: Follow-up surveys. &
\end{tabular}

TABLE 12 Serious Adverse Events

\begin{tabular}{lll}
\hline Number & Description & Treatment \\
\hline NIL & NIL & NIL \\
\hline Data source: Case report forms.
\end{tabular}




\section{Discussion}

Almost half (47\%) of the ring's users were between the ages of 20 and 29-an age range when fertility is highest and family spacing need is greatest. The PVR, when introduced, will add to the available options for these mothers during the immediate postpartum period, and help meet the substantial unmet need (over $65 \%$ ) during this period. It also appears that first-time users of family planning preferentially chose the PVR in this study, as over $62 \%$ of the participants were first-time users. Curiously, a study of 2,000 women seeking family planning in $\mathrm{UCH}$ Ibadan (one of the study sites) revealed that the majority of the women made their choice of methods following advice from friends and family members (Konje et al. 1998). Yet many first-time users who supposedly had received similar advice from friends and family members opted to use the PVR. This may suggest the extent to which the women found the ring appealing. Also, the fact that more than $36 \%$ of the users have three or more children and $50 \%$ wanted to delay their next pregnancies by at least two years indicates potential gaps that need to be filled. This is in line with findings from the recent NDHS (2013) where $67 \%$ of women do not want to have a baby within two years of their last birth. Therefore, should the PVR become available in the country, demand for the product would likely be high.

This study revealed findings of interest that may influence future decisions in terms of registering the ring in Nigeria and its potential for adding value to the postpartum family planning landscape. The fact that it took only 97 women to be screened for eligibility in order to enroll the 58 required for the study (eligibility rate of $60 \%$ ) is a testimony to the suitability of the PVR for many women. This is notwithstanding the strictest eligibility criteria applied for the study, some of which will not apply in routine clinical use. Another encouraging outcome is that up to $81 \%$ of the recruited women continued with the ring for up to six months. This is a big achievement for the ring given the knowledge that up to $50 \%$ of women discontinue their current method of choice within six months of initiation. And of the 11 users who terminated early, only $3(27 \%)$ reported side effects as the reason for discontinuing the ring. This is comparable to a discontinuation rate of $29 \%$ due to side effects associated with injectable contraceptives in Nigeria (NDHS 2013).

Although up to $47 \%$ of the participants indicated that one of the reasons why they chose the PVR was because it was given free, it seems the price alone could not have determined their choices. This study was conducted in public facilities where all other methods were equally free, the exception being that choosing methods other than the PVR would attract a service charge that is marginal and should be easily affordable given the urban locations of the study facilities and the relatively high socioeconomic status of the participants. For example, the Willingness To Pay (WTP) study conducted in the same facilities showed that all the women interviewed were willing to pay for the ring if it is available at N300 (about US $\$ 2$ ), and N300 is the median price for injectable contraceptives within the private sector in Nigeria. Thirty-six percent of women chose the ring because it is user-initiated and controlled. This is a very important attribute of the ring considering the general service environment where rural dwellers lack access to skilled providers and are unable to access highly effective methods especially during a period of greatest need.

Among participants, the most common methods used previously were injectable contraceptives (10\%) closely followed by implants ( $9 \%$ ) and then contraceptive pills (7\%), male condoms (7\%), IUDs (3\%), and emergency contraception (2\%). Looking at the contraceptive need for the immediate postpartum period, for which the PVR is specifically designed, combined oral contraceptive pills are not an option until after 6 months (WHO 2015). Similarly, access to injectables, IUDs, and implants requires family planning infrastructure with trained providers. The male condom is also not ideal for family planning purposes, given that it is coitally dependent and has a high failure rate in typical use. This suggests that when the PVR becomes available, it will expand choices for breastfeeding mothers. Because of the user-controlled aspect, it can be provided at both public and private clinics as well as in rural areas through patent medicine vendors (PMVs) and Community Health Extension Workers (CHEWs). 
One concern that was frequently expressed was whether Nigerian women can easily insert and remove the ring by themselves, given the cultural sensitivity to touching one's genitalia. This study showed that this fear is unfounded, as all participants found the ring either easy or very easy to insert. The ability to insert and remove the ring does not seem to be associated with continuation or termination, as all of those who terminated had no problem removing the ring.

Almost all who discontinued the study reported that their partners felt the ring during sexual intercourse, while only $28 \%$ of those who completed the study had the same complaint. Contribution of psychological factors to this observation must be ruled out as this was a concern among all stakeholders and family planning service providers during the stakeholder dialogue and mapping prior to conducting the study. This complaint also persisted among the women themselves, with $21 \%$ and $100 \%$ of women feeling the ring at intercourse among the completers and early terminators, respectively. Because of this concern, $50 \%$ of early terminators removed the ring during sexual intercourse as opposed to only $5 \%$ of the completers. While the influence of psychological factors is a strong possibility, future introductory effort must ensure that the women are taught how to push the ring high enough into the posterior fornix. As this is a new method utilizing vaginal route for administration, it will take some time for the population to overcome this concern.

Another concern that was frequently voiced was the possibility of recurrent vaginal infection if the ring is left in the vagina for a long time. The evidence from this study supports the literature that states that ring usage does not increase vaginal infections. The only method-related complication reported was abnormal vaginal bleeding, which was mild in the three cases reported. All three cases were mainly spotting and the longest bleed lasted for only three days. This is a relatively common experience with most progestogenic agents, such as injectable contraceptives, implants, and the Levonorgestrel Intrauterine System (LNG IUS). As with other progesterone-based agents, the symptom is self-limiting and was effectively managed with proper counseling and reassurance. No serious adverse event was reported in this study.

Further discussions and interviews with selected women users and their spouses, family planning providers who recruited and monitored the women, as well as community stakeholders provided deeper insight into their perspectives, which is relevant to our understanding of how the ring is introduced. For example, women have reported that the use of the PVR does not seem to affect the quality and quantity of their breast milk nor does it cause serious side effects. They are also very comfortable inserting the rings by themselves and their sexual lives were unaltered as a result of using the ring.

\section{ACCEPTABILITY}

Using the continuation rate as a measure of acceptability, the acceptability in this study is very high; more than $81 \%$ of participants continued the method for two rings cycles (six months). This observation is corroborated by other findings from the study. For example, although there was some hesitation on the part of providers during orientation training and on the part of users at enrollment, eventually women accepted inserting and removing the rings by themselves and continued to do this throughout the study period. With few exceptions, women and their partners generally were happy leaving the rings in their vaginas during intercourse. In one instance, a couple reported enhanced sexual pleasure when the ring was in place. Participants also reported unaltered breastfeeding volume and that their babies' health remained sound throughout the length of time they used the ring.

One remaining challenge is how to address some of the concerns of community stakeholders, because their misperceptions can influence how the ring is perceived when eventually introduced. For example, one stakeholder said that the chemical in the ring could have an effect on the babies. This is the kind of misperception that must be dispelled. 


\section{LESSONS LEARNED FOR FUTURE INTRODUCTION OF RINGS}

This study reveals a number of lessons that must be considered while the product is being registered, introduced, and distributed:

- Clearly the introduction of the PVR will be a welcome development for the family planning service environment in Nigeria. The attitudes of the women and their spouses, and those of the providers toward the ring changed markedly by the end of the study. This is the first requirement of commodity introductory efforts.

- About $62 \%$ of participants were first-time users of family planning and chose to use the PVR despite the availability of other established methods. In a society where family planning method choice is generally based on recommendations by significant others, this may indicate the huge potential of the PVR to add value to the postpartum family planning landscape in Nigeria.

- It is good practice to remember that initial impressions and perceptions about a product being introduced may not necessarily be the same after actual use. At the end of the study, both the family planning providers and women participants expressed the opinion that the PVR is "one size fit all."

- The benefits of stakeholders' engagement from the outset cannot be overemphasized. Early collaboration in this project with the FMoH and regulatory bodies such as NAFDAC is paving the way for a seamless registration process in the country and creating support from partners for the ring's inclusion on the national Essential Medicines List.

- Involvement of training institutions and professional bodies in the planning and implementation phase of the project can catalyze the uptake and consumption of new ideas by the target elements. In one of the study centers, which is a teaching institution for medical and nursing students, the PVR is already integrated in the curriculum for medical students. This will ensure that cohorts of future generations of doctors are exposed to the ring right from their schooling years. This is in addition to the number of obstetricians and gynecologists who were trained as local resource persons. This bodes well for future introductory efforts.

- For any new commodity to be successfully introduced, the community must be sensitized well ahead of time to mitigate the possibility of misperceptions that could be difficult to eradicate once established. To this end, the Council is already partnering with a coalition of Civil Society Organizations (CSOs) to engage the community in a positive manner and to obtain feedback that would help situate the ring in a rights-based framework.

- The interest that the national government has in the ring must be sustained, especially with the recent change of government at all levels. Luckily, the successful registration and introduction of the PVR is one of the priority areas of reproductive health interventions submitted to the new government by the Coalition of Civil Society Organizations in Nigeria. 


\section{References}

Borda, M.R., Winfrey, W. and McKaig, C. (2010) Return to Sexual Activity and Modern Family Planning Use in the Extended Postpartum Period: An Analysis of Findings from Seventeen Countries. African Journal of Reproductive Health, 14, 75-82.

Bradley, Sarah E.K., Trevor N. Croft, Joy D. Fishal, Charles F. Westoff. 2012. Revisiting Unmet Need for Family Planning. DHS Analytic Studies No 25. Calverton, MD, USA, ICF International.

Haggerty, Patricia A., and Rutstein, Shea O. 1999. "Breastfeeding and complimentary infant feeding and the postpartum effects of breastfeeding". Macro International.

Konje, J.C., F. Oladini, E.O. Otolorin, O. Ladipo. 1998. "Factors determining the choice of contraceptive methods at the family planning clinic, University College Hospital, Ibadan, Nigeria." The British Journal of Family Planning 24(3): 107-110.

Massai, R., P. Miranda, P. Valdes, P. Lavin, A. Zepeda, M.E. Casado, et al. 1999. "Pre-registration study on the safety and contraceptive efficacy of a progesterone-releasing vaginal ring in Chilean nursing women."

Contraception 60: 9-14.

Population Reference Bureau. 2012. “World population data sheet.” Accessed 11 August 2015.

http://www.prb.org/pdf12/2012-population-data-sheet eng.pdf

Reproductive Health Supplies Coalition [RHSC]. 2011. "Progesterone-only vaginal rings." Product Brief, Caucus on New and Underused Reproductive Health Technologies.

Sivin, I., S. Diaz, H.B. Croxatto, P. Miranda, M. Shaaban, E.H. Sayed, et al. 1997. “Contraceptives for lactating women: A comparative trial of a progesterone-releasing vaginal ring and the copper T 380A IUD." Contraception 55: 225-232.

World Health Organization. 2015. Medical Eligibility Criteria. Accessed 11 August 2015. http://www.who.int/reproductivehealth/publications/family planning/Ex-Summ-MEC-5/en/ 


\section{Appendix}

\section{APPENDIX A1: INCLUSION/EXCLUSION CRITERIA}

\section{A. INCLUSION CRITERIA}

To participate in the study, a woman must meet all the inclusion criteria listed below at enrollment:

1. Able to provide informed consent

2. Age 18 to 35 years (inclusive)

3. Has delivered a healthy singleton infant 6 to 9 weeks prior to study enrollment

4. Has at least (1) living child and is fully/nearly fully breastfeeding the new infant

5. Willing to continue breastfeeding infant a minimum of 4 times per day for at least 6 months

6. Is in good health as confirmed by medical history, physical examination. (Includes vital signs and diagnosis/treatment of vaginal infection per the standard of care in Nigeria. Treatment of vaginal infection, if any, is required prior to enrollment.)

7. Has or expects to have regular exposure to the risk of pregnancy

8. Willing to choose the PVR as contraceptive method

9. Willing and able to follow study procedures

10. Expects to continue living in an area accessible to the study site for the duration of the study

\section{B. EXCLUSION CRITERIA}

Similarly, women with any of the following attributes were excluded from participating in the study:

1. Is pregnant or suspected of being pregnant

2. Breastfeeding less than fully/nearly fully

3. Hypersensitivity to hormonal preparations or silicone rubber

4. HIV positive or in a discordant relationship

5. Presence of genital or urinary tract infection

6. Dyspareunia

7. History of Human Papillomavirus (HPV)

8. History of bacterial infections such as Chlamydia and gonorrhea

9. History of pelvic inflammatory disease (PID) or salpingitis since delivery

10. History of chronic constipation

11. Clinically relevant genital prolapse

12. Has history of generalized urticaria

13. Any chronic condition requiring continuous or regular use of medication or herbals prescribed by healers

14. Has a history of thrombophlebitis or thromboembolism

15. History of and/or current depression

16. History of epilepsy or convulsive disorder

17. Had an ectopic pregnancy

18. Has vaginal bleeding not attributable to menses

19. Known or suspected carcinoma of the breast

20. Has had any other known or suspected neoplasia within last 5 years

21. Not exposed to risk of pregnancy

22. Use of chronic medications, Rifampicin, Griseofluvin, barbiturates, phenytoin, ketoconozole, butazoliden

23. Confirmed hypertension (blood pressure-systolic more than $140 \mathrm{mmHg}$ and/or diastolic of more than $90 \mathrm{mmHg}$ 
Population Council House 4, No. 16b, POW Mafemi Crescent Abuja, Nigeria popcouncil.org 